Article

\title{
A Resilience-Based Approach to the Conservation of Valley Oak in a Southern California Landscape
}

\author{
James J. Hayes ${ }^{1, *}$ and Shanon Donnelly ${ }^{2}$ \\ 1 Department of Geography and Geology, University of Nebraska at Omaha, Omaha, NE 68182, USA \\ 2 Department of Geosciences, University of Akron, Akron, OH 44325, USA; \\ E-Mail:sd51@uakron.edu \\ * Author to whom correspondence should be addressed; E-Mail: jjhayes@unomaha.edu; \\ Tel.: +1-402-554-3862; Fax: +1-402-554-3518.
}

Received: 21 April 2014; in revised form: 10 July 2014 / Accepted: 14 July 2014 /

Published: 23 July 2014

\begin{abstract}
Conservation thinking will benefit from the incorporation of a resilience perspective of landscapes as social-ecological systems that are continually changing due to both internal dynamics and in response to external factors such as a changing climate. The examination of two valley oak stands in Southern California provides an example of the necessity of this systems perspective where each stand is responding differently as a result of interactions with other parts of the landscape. One stand is experiencing regeneration failure similar to other stands across the state, and is exhibiting shifts in spatial pattern as a response to changing conditions. A nearby stand is regenerating well and maintaining spatial and structural patterns, likely due to the availability of imported water associated with upstream urban development. Valley oak stands have a capacity for reorganization as a response to changes in the landscape and environmental conditions. This reorganization can benefit conservation efforts; however, we must ask what limits there are to valley oak's capacity to reorganize and still maintain its ecological function in face of increasing changes in climate and land cover. The usefulness of resilience as a concept in conservation is discussed at several scales from the stand to the landscape.
\end{abstract}

Keywords: conservation; landscape; valley oak; resilience; California; imported water 


\section{Introduction}

Climate change and other human-induced modifications in land use and land cover are presenting novel conditions to which ecosystems and conservationists must respond [1,2]. Recognizing the importance of spatial and temporal dynamics in landscapes is necessary as conservation responses to new conditions develop. Increasingly, conservationists recognize that restoring an idiosyncratic ecological pattern or working to maintain a system in equilibrium is problematic. Ecosystems and landscapes have functions beyond maintaining a particular pattern of composition and arrangement, and any current landscape pattern is only one manifestation of dynamic processes that can produce many possible outcomes emerging from a complex system of biophysical and social interactions [2,3-5].

While the notion that no patch of land, preserve, or landscape can be independently preserved and isolated from the broader environment goes back many years, perhaps to George Perkins Marsh [6], it is only in the last few decades that conservationists began to incorporate the ideas of "ecosystem management" [7-9] and "landscape management" [10-13] into conservation planning. Today conservationists are increasingly aware of spatial and temporal dynamics that affect local conditions and have implications for perhaps distant ecosystems connected through exchanges of biomass, energy, nutrients, and genetic material. The concept of teleconnections [14] is emerging in land change science as a means to describe these distal connections. Landscape ecology has improved our understanding of the importance of spatial phenomena including the heterogeneity, size, shape, and connectedness of landscape elements [15-17]. One result of this improved understanding is efforts to focus on connecting habitats across larger areas, developing regional conservation plans to allow for the continued dispersal of organisms, abiotic flows, and processes, through landscapes that are filling in with new types of habitat or land cover that might act as barriers or alter these processes (e.g., The Rim of the Valley Corridor in southern California (US National Park Service) [18]. Yet even as these ideas of landscape ecology are implemented, conservation practices within the assembled mosaic of habitats and corridors tend still to focus on facilitating or retarding particular flows, maintaining a particular composition and structure of species and populations, or to restore a historical composition and structure from a past point in time [2].

Taking the view that a landscape is a complex social-ecological system, we suggest a resilience approach to conservation applied at the landscape scale. Resilience has been defined as the capacity of a system to absorb disturbance and re-organize while undergoing change so as to still retain essentially the same function, structure, identity, and feedbacks [19]. The components and connections that comprise a landscape are continually changing to produce emergent outcomes. Human activity to arrest this process in a desired state requires high inputs of energy, matter, and information, making the ecosystem increasingly costly to maintain, and may alter the capacity of a landscape to self-organize [20]. Connections among landscape elements exist with or without planned conservation corridors to maintain connectivity. Just as an individual conservation reserve cannot be isolated from the broader environment, a regional conservation mosaic of patches and corridors cannot be isolated, and both are parts of a human-environment system. Rather than attempting to guide or control the structural and spatial outcomes of ecological processes, an approach that allows spatial and temporal patterns of composition and structure to change within identifiable thresholds, while maintaining ecological functions, may be more realistic. 
A resilience approach to landscape conservation must be flexible, allowing landscape features, such as nature preserves, to adjust and respond to changing conditions in other parts of the landscape. Such an approach starts with adaptive management practices at the patch level and extends them to consider the broader functioning of the landscape system as a whole. This will require imagination, creativity, and an open mind to pragmatic plant and animal communities and habitats that may be unfamiliar, but continue to support broader ecological functions within the landscape.

We discuss the idea of landscape as a complex ecological system in the context of two nature reserve sites in the Santa Monica Mountain National Recreation Area, California, USA. Each of the sites hold stands of Quercus lobata (valley oak), an endemic California oak experiencing habitat loss and regeneration failure throughout the state. Climate change threatens valley oak as well due to potential range contraction as its climate window shifts northward. While valley oak is of concern to conservationists across California and around the world, what is of particular interest to this paper is how these two sites within $5 \mathrm{~km}$ of one another have experienced different spatial and temporal dynamics. We expect that differences in landscape connections and ecological flows as a result of environmental change in the surrounding landscape will lead to different outcomes for the two sites. In the context of regional drought and increasing landscape development we ask whether valley oak here shows signs of the regeneration failure seen elsewhere and how landscape patterns manifest themselves in this context. Specifically we examine the habitats within these sites where valley oak stems have established in the past, and where and if they are currently regenerating.

\subsection{Resilience and Landscape}

As with ecosystems generally understood, the landscape ecosystem is an open system with inputs and outputs of energy, matter, and information. Thinking of the landscape as an open system lends itself well to a general systems approach. This general systems approach is a strength of the landscape ecosystem we found expressed in Malanson's [21] view that "general systems theory provides a rationale" for combining reductionist and holistic approaches to eliminate peripheral questions while maintaining analysis of interactions among phenomena. Stoddart [22,23] has elaborated on the applicability of a systems approach in geography and Homer-Dixon [20] applied the idea of energy input and output to explain the rise and fall of the Roman Empire in terms of energy required to develop and sustain the Empire's material and social structure.

Landscape features interact with each other and a complex systems approach is helpful in understanding how. Features are dynamic subsystems at one scale and may change from one type to another for various reasons. At the landscape scale, the strength and route of connections change between features. As an open system, matter, energy, and information are also flowing into and out of the landscape. While the interchangeability of matter and energy are frequently discussed, the inclusion of information with these is less common, but necessary, when attempting to include all features in the landscape. We follow Stonier [24] in defining information in terms of its capacity to organize a system. While both human social rules and physical rules govern feature interaction, these rules are not static, and features self-organize to better operate in response to these rules as they change. These feedbacks cause learning that is remembered, reapplied in future scenarios, and modified through time. This notion of a dynamic, learning landscape is essentially a description of 
a complex system exhibiting aggregate complexity as described by Manson [25]. Further, Malanson [21] has suggested that geography is particularly well suited to contribute to complexity science because of the discipline's focus on the creation of place through emergent outcomes dependent on location, and O'Sullivan [26] has noted the particular applicability of aggregate complexity within geography.

Manson [25] identified six key attributes of aggregate complexity: relationships, internal structure, environment, learning and memory, emergence, and change and evolution. The shift towards understanding emergent properties of social-ecological systems, such as the presence of valley oak, requires focusing on the relationships and internal structure of the system. This again reinforces the need to include all of the components of the system, both human and natural. Understanding the evolution of a system, driven both by changing internal structure and from external environmental influences, is necessary to elucidate if the social-ecological system exhibits learning and memory that may increase future resilience.

This conception of landscape as a system of features that are interacting via exchanges of matter, energy, and information fits well with the notion of aggregate complexity described above. The flows of matter, energy, and information are the relationships that tie features together and are reorganized over time in reaction to internal and external forces. Some relationships happen over fine scales, such as surface flow of water, or predation, and some relationships happen over much broader scales, such as climate effects on landform development, and vegetation. For example, Mclaughlin and Zavaleta [27] discuss different factors likely influencing valley oak recruitment differently at the site and regional scales. To address the conservation of valley oak in terms of resilience in this landscape is to ask how the system can and cannot change at the site scale while retaining the species as a functional landscape component.

Fundamental to thinking about the resilience of a landscape as a social-ecological system is the notion that these systems are constantly changing. That is change, rather than equilibrium, is the norm and may appear linear near one stable state but is frequently non-linear in far from equilibrium states [28] where thresholds between multiple stable states exist. Holling and Gunderson [29] describe this generalized cycle of change in terms of four stages: exploitation, conservation, release, and reorganization. This adaptive cycle happens at multiple scales that interact with one another such that finer scales move through the cycle more quickly and broader scales more slowly. The small, fast cycles provide constant change and the large, slow cycles provide boundaries for that change [30]. Key to the application of this maturing body of theory to conservation concerns is the clarification of "resilience of what to what?" [31].

\subsection{Valley Oak}

Valley oak (hereafter QULO) faces a number of conservation challenges and has been the focus of much attention due to concerns about regeneration failure [32-34], habitat fragmentation and modification [35], and habitat shifts associated with climate change [36-40]. Climate change and continued land cover change are expected to further isolate QULO, limiting it to the coolest and wettest sites while also contracting its range [36]. However, the species is established across wide gradients of precipitation, temperature, and seasonality - variables forecast to change spatially and temporally in different ways - making generalizations about the spatial response difficult [39]. 
Valley oak is a deciduous species that is both flood and drought tolerant. Adult QULO are typically 10-25 $\mathrm{m}$ tall and 50-70 $\mathrm{cm}(\mathrm{dbh})$, but can be much larger [41]. The trees are long-lived and mature stands are typically 100-200 years old [42]. Though heart-rot in older trees makes exact dating very difficult it is estimated that some trees may live 400 to 500 years [32,42]. Valley oak is the dominant species in QULO woodland and QULO riparian forest. Valley oak woodland is savanna-like with widely spaced individuals and occasional clumps of several adults amid annual grassland. The stands are usually found in valley bottoms and floodplains associated with deep, fertile soils [35].

Changing climatic variables combined with landscape development presents challenges for conservation of QULO, and ecological conservation more generally, as species respond to changing conditions [1] and reorganize themselves on the landscape. Alterations in the structure and distribution of QULO stands could affect a number of related species and processes including woodpeckers, predatory birds, pollinators, seed dispersers, arboreal and burrowing mammals, and reptiles, as well as rates of soil and landform development [35,43]. Demographic studies and inferences about the regeneration problem in QULO stands remain inconclusive when examined on the whole [37,38], although recent work has shed more light on long term demography and response to climate and disturbance $[39,40,44]$. While most studies have found seedlings and saplings to be absent or rare (e.g., $[32,45,46])$ it is difficult to generalize from these findings because of the focus on a single sites at a single point in time [38,39]. Results of demographic studies vary considerably with site-level characteristics as well, such as whether the site was grazed, the amount of precipitation in years immediately preceding the survey, and climatic conditions of the site [37]. Tyler et al. [47] noted that rates of oak recruitment have been lower in savannah than woodland settings elsewhere; they cited lower adult tree density and reduced probability of dispersal as a potential cause. Valley oak seedling growth has been positively correlated with soil moisture [48] and lower groundwater levels associated with QULO mortality [34], suggesting the importance of changes to the hydrologic regime. McLaughlin and Zavaleta have found QULO may be already shifting to cooler and wetter micro-climate refugia [40], and that recruitment has occurred to varying degrees at $70 \%$ of sites initially surveyed 20 to 40 years ago [27].

Recruitment levels found in previous studies do not seem to be associated with independent variables such as location, precipitation, or land management regimes, with the caveats that designation of a site as a nature preserve was associated with the probability of regeneration presence [38] and that research reserves were found to have lower recruitment than other management regimes [27]. We are aware of no studies of QULO stands that consider them in a systems framework.

\section{Methods}

The sites compared in this paper are Cheeseboro Canyon (CHE) and Paramount Ranch (PAR), both conservation areas within the Santa Monica Mountains National Recreation Area, managed by the US National Park Service (NPS) (Figure 1). The sites have complicated ownership and land use histories including livestock grazing and dry-land farming. The predominant use of the sites now is for hiking, mountain biking, and horseback riding. Paramount Ranch was intensively used for film and television production until around 1980, and it is still used for this on a limited basis as approved by the NPS. Grazing continued at CHE into the late 1980s when NPS began acquiring the land. Grazing no longer 
occurs at either of the sites. Valley oak planting efforts have begun at CHE to aid recruitment and the GPS coordinates of planted saplings are recorded by the NPS - these planted trees were not included in data reported here.

Figure 1. Sapling and adult stems are mapped on a $7 \mathrm{~m}$ contour interval map shown against a 10 m DEM. (a) Saplings at Cheeseboro Canyon (CHE) are found primarily along the stream and road corridor on the west side of the site; (b) Saplings at Paramount Ranch (PAR) are distributed similarly to adult stems; (c) The study sites are located approximately $5 \mathrm{~km}$ apart on the north slope of the Santa Monica Mountains National Recreation (SAMO) in southern California.

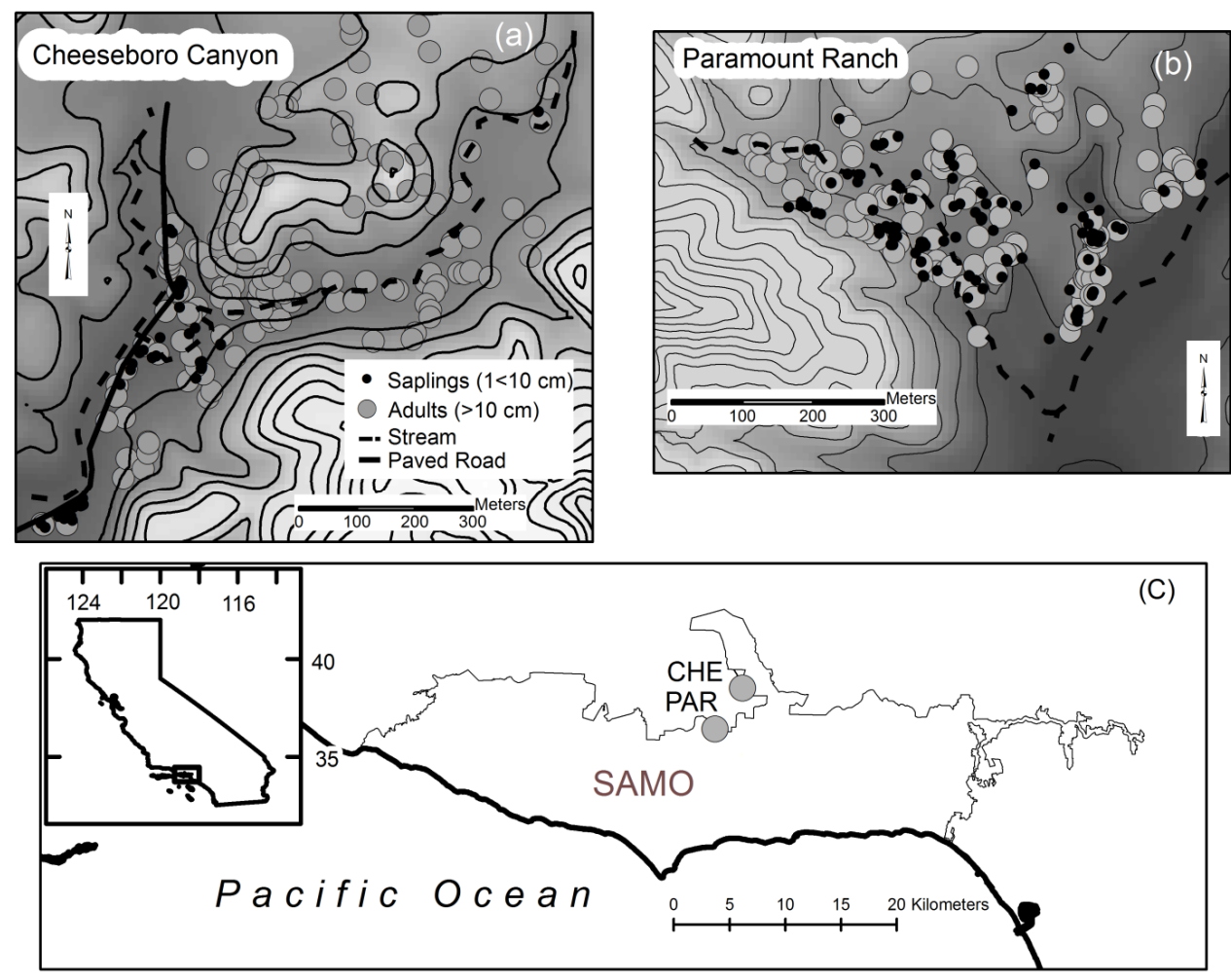

Both sites are sub-watersheds within the Malibu Creek Watershed. The Malibu Creek Watershed was largely undeveloped until the arrival of a state water project (SWP) that brought municipal water to the area in the 1960s. CHE is at the terminus of a subwatershed drained by Cheeseboro Canyon and Palo Commado Canyon. Several streams, mostly channelized and concrete armored, drain the PAR subwatershed and flow into Madea Creek which runs through the PAR site (Madea Creek is not armored). Perhaps the most dramatic difference between the sites is the degree of land cover change experienced within the sub-watershed of each site. Home construction increased and impervious surface area with it following the arrival of the SWP (Orton pers. comm.) [49]. Currently the CHE sub-watershed is primarily open space (area enclosed by dashed line in Figure 2), with $2.1 \%$ impervious surface or urban land cover, while the PAR sub-watershed (entire area shown in Figure 2) is $25.8 \%$ urban land cover. The CHE watershed is contained within the PAR watershed. The watersheds shown in Figure 2 were calculated using the hydrologic modeling tools in ArcGIS 10.2.1 using a Digital Elevation Model (DEM) with $10 \mathrm{~m}$ resolution. Land cover was reclassified from the National Land Cover Dataset 
(USGS NLCD 2006) [50] to urban, woodland, and low vegetation. Stream gage records from Malibu Creek, downstream of both CHE and PAR, indicate increased discharge following both the SWP and increasing development in the watershed. We examine the spatial and temporal dynamics of QULO stands in the context of this upstream land cover change and increased urban runoff.

Figure 2. Land cover in the CHE and PAR subwatersheds of the Malibu Creek Watershed. Entire land cover data extent is the watershed of PAR. Area enclosed by dashed line is the watershed of CHE. The watershed of CHE is contained in the watershed of PAR.

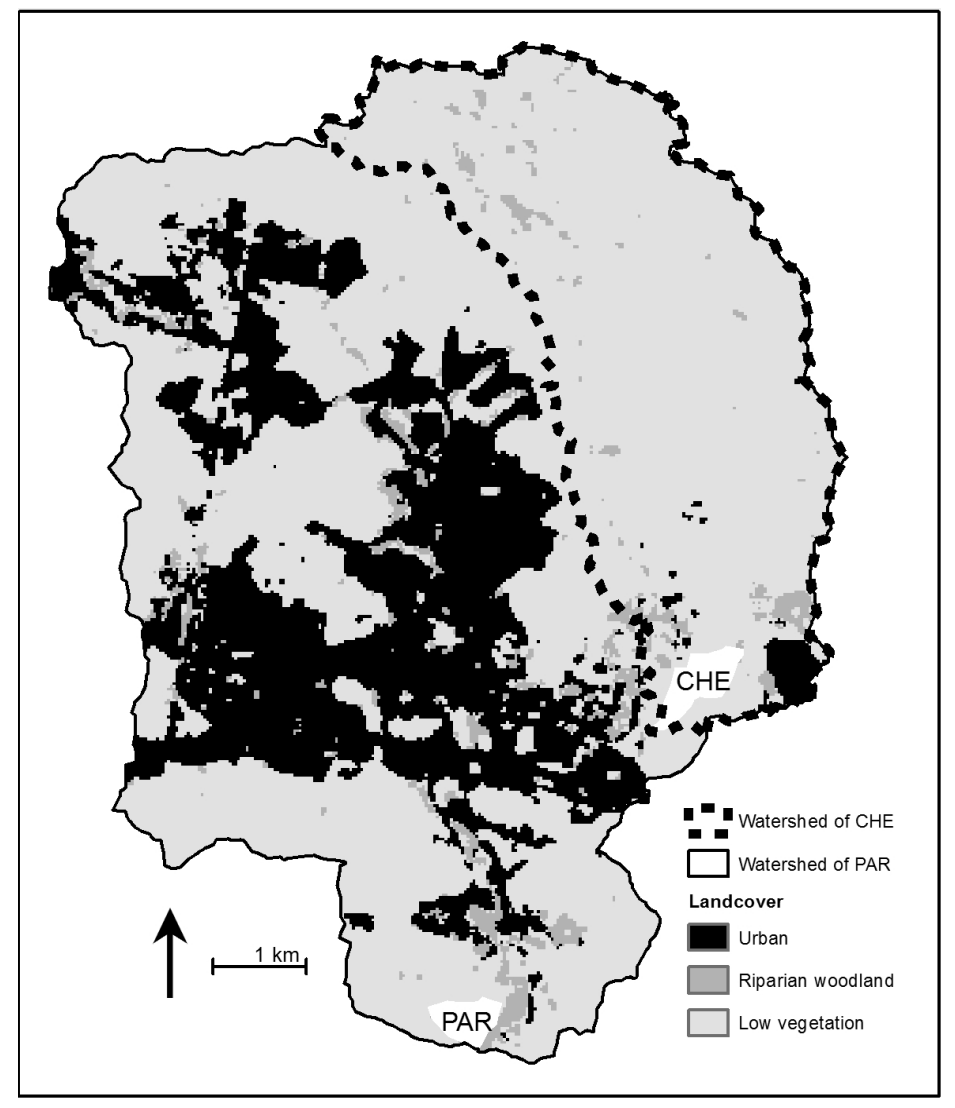

To assess stand structure and spatial dynamics we collected data on stem diameter (dbh), location (UTM coordinates), and topographic position. We also calculated the distance from each stem to the nearest stream. To examine regeneration and whether saplings are differing in establishment patterns from past adult establishment we distinguished between adult stems $(\mathrm{dbh} \geq 10 \mathrm{~cm})$ and sapling stems $(1 \leq \mathrm{dbh}<10 \mathrm{~cm})$. All stems greater than $1 \mathrm{~cm}$ dbh were measured and mapped at both sites.

To examine associations among adult and sapling establishment sites we recorded the topographic position of each stem along a categorical gradient (floodplain, swale, hillside, or hilltop) and within slope aspect classes. Stem dbh and location were recorded using a Garmin GEOXH GPS (average accuracy $30 \mathrm{~cm}$ ) and stored in an ArcGIS geodatabase. Stems were designated with a hillside classification if they were found on a shoulder, backslope, or footslope position. Aspect was recorded for stems found on hillside positions. A 10 m resolution USGS National Map DEM was classified into topographic and aspect categories to determine the proportion of each study site occupied by 
the topographic and aspect classes. Finally, a streams layer was digitized from USGS Digital Orthophotos to allow analysis of the distance between stem locations and the nearest stream channel.

Using the above data, the proportion of stems found in each topographic and aspect class was calculated to assess patterns in the distribution of QULO stems among topographic position classes. In addition, the distance of each stem to the nearest stream was calculated using the "near" command in ArcInfo 9.2 [51]. These calculations allowed us to ask two specific questions: is the proportion of stems that is found in a particular topographic class approximately equal to the proportion of the study site occupied by that class; and, is the median distance between stems and stream channels changing for smaller trees. We asked these questions for all of the stems at each site, as well as for adult stems $(\mathrm{dbh} \geq 10 \mathrm{~cm})$ and sapling stems $(1 \leq \mathrm{dbh}<10 \mathrm{~cm})$ to assess whether patterns in stem establishment were changing. The above methods are discussed in more detail in Hayes [52].

\section{Results}

Examination of the dbh data revealed two very different size-class distributions at the two sites. Although saplings were the most abundant stem size at both sites, the distributions differed from there (Figure 3). Sapling stem density was much higher at PAR than at CHE and PAR had a much more even size-class distribution for stems $\mathrm{dbh}>20 \mathrm{~cm}$. Sapling to adult ratios were 0.5 at $\mathrm{CHE}$ and $>1$ at PAR. In addition, CHE had a near absence of stems in the $20 \mathrm{~cm}-40 \mathrm{~cm}$ dbh range, suggesting past recruitment failure or disturbance. Tree size was larger on average (median) at CHE, but also more variable, than at PAR.

Mapping the stems reveals that saplings are more spatially restricted at CHE than at PAR, in addition to being fewer and lower in density (See Figure 1a,b). Saplings at CHE are exclusively found along an intermittent stream channel, roughly paralleling a paved road running past the site. Conversely, saplings at PAR appear more widely distributed across the site and in similar proportion to adult stems. These observations are supported by categorical habitat mapping of saplings and adult stems, as well as examination of distance of stems to the nearest stream.

The proportion of stems found in each topographic class was disproportionate to the area occupied by the topographic classes, with the exception of adult stems on hillsides at CHE and hilltops at PAR where the proportions were similar (Figure 4). In general, for both sites, floodplain and hillside classes had a higher proportion of stems than the proportional area of those classes, and swale and hilltop classes had lower proportions of stems than expected, given the proportion of the study sites those classes occupied. Adult stems were found in all topographic class at CHE, yet saplings were absent in all but the floodplain. The proportion of adult stems occurring in floodplain and hillside positions (combined) was over 0.80 at both sites. At PAR more than half (0.56) of all adult stems were found on hillsides and over a third at CHE (0.37). Additionally, 0.68 of saplings at PAR were found on hillsides; however, no saplings were found on hillsides at CHE. While half of all adults (0.54) were found in the floodplain at CHE, all saplings were found there. The proportional distribution of stems among aspect classes indicated similar differences between the two sites (Figure 5). Although adult stems at CHE were found on a variety of hillside aspects, no saplings were found on hillsides in any aspect class. At PAR saplings tended to occur at similar proportions as adults, with the exception of 
NE facing slopes where saplings had a higher proportion (0.47) than adults (0.23) and on E facing slopes where adults were more abundant $(0.26)$ than saplings $(0.16)$.

Figure 3. Size class distributions (10 cm dbh increments) of QULO stems at (a) CHE and (b) PAR. CHE had fewer stems overall and fewer saplings. A conspicuous gap in the distribution at $\mathrm{CHE}$ indicates past regeneration failure or disturbance as saplings failed to survive into the 30 and $40 \mathrm{~cm}$ size classes. Sapling mortality is noticeable at PAR; however, saplings are still surviving into larger size classes and the distribution of stem size is more even at PAR with similar numbers of old and young stems.
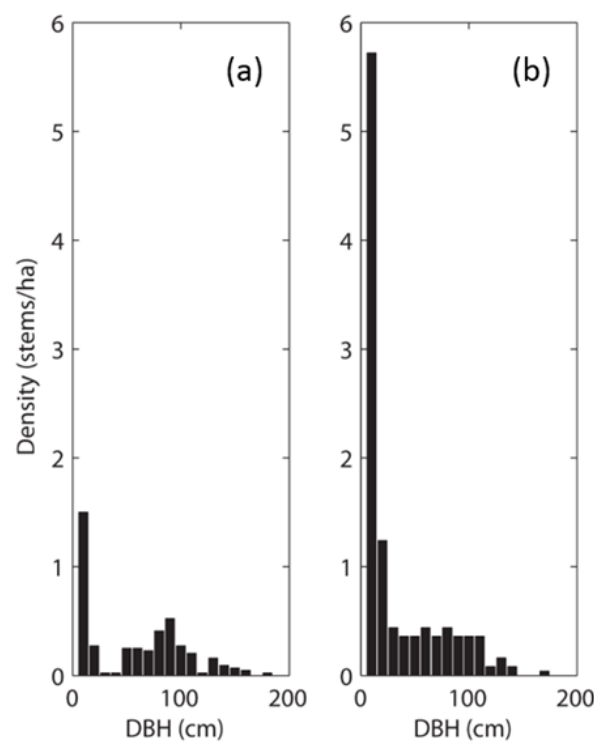

Figure 4. Comparison of proportional area of each site occupied by four topographic classes and proportion of adult and sapling stems found in the topographic classes. At CHE the proportion of adult stems in the floodplain and hillside classes was similar to the proportional area of those classes. Saplings at CHE were unevenly distributed with all sapling stems occurring only in the floodplain class. Adult and sapling stems at PAR tended to be unevenly distributed among the topographic classes; comparatively few stems were found in swales, while a relatively high proportion of stems were found on hillsides. The proportion of stems found on hilltops at PAR was similar to the proportional area of that habitat.

\section{CHE Adult Topographic Distribution}

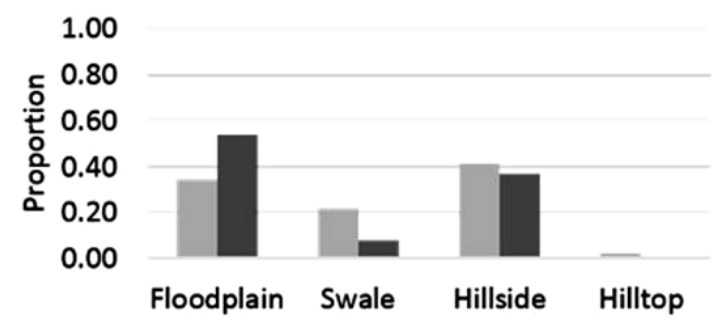

CHE Sapling Topographic Distribution

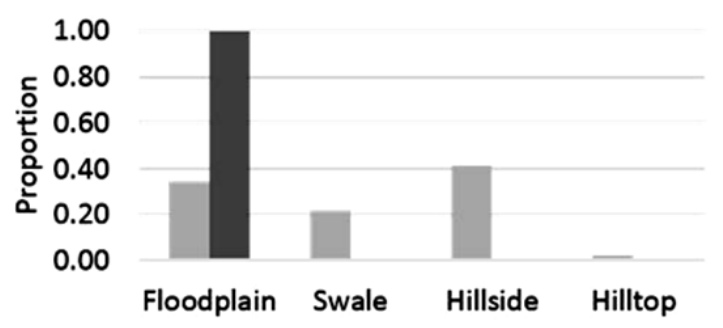


Figure 4. Cont.
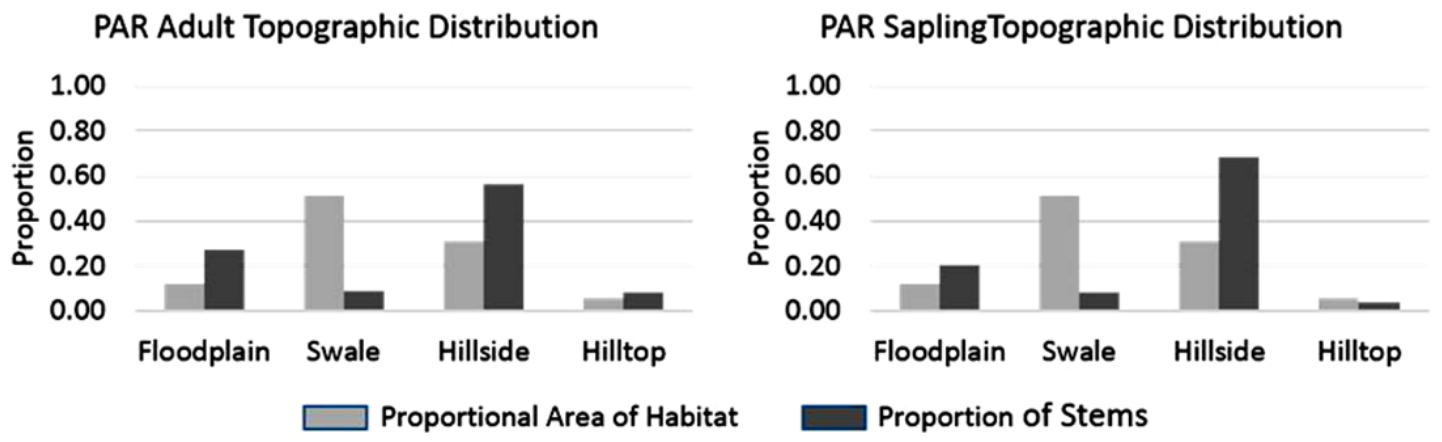

Figure 5. Comparison of proportional area of each site occupied by eight aspect classes and proportion of adult and sapling stems found in the aspect classes. No saplings were found on hillsides at CHE and therefore the proportion of saplings is zero for all classes. Adult stems at CHE were disproportionately found on west and northwest facing hillsides, while at PAR both adults and saplings were primarily found on north, northeast, and east facing aspects.

\section{CHE Adult Aspect Distribution}

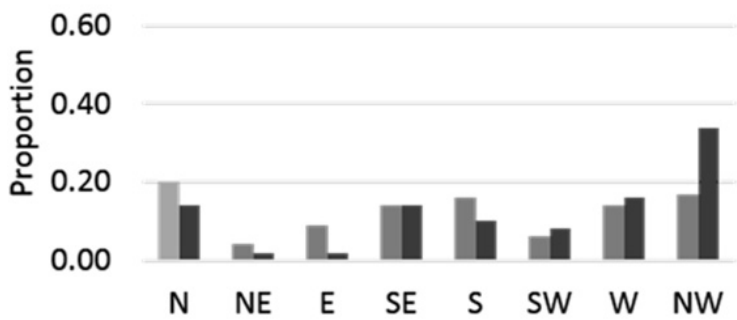

PAR Adult Aspect Distribution

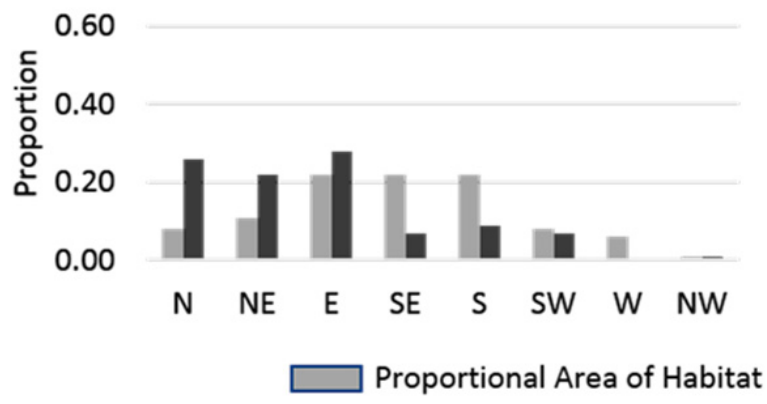

\section{CHE Sapling Aspect Distribution}

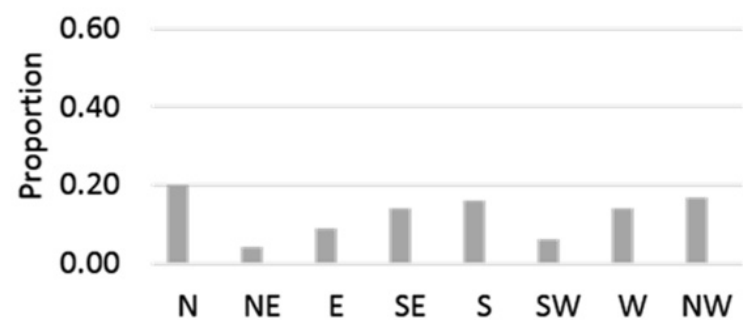

PAR Sapling Aspect Distribution

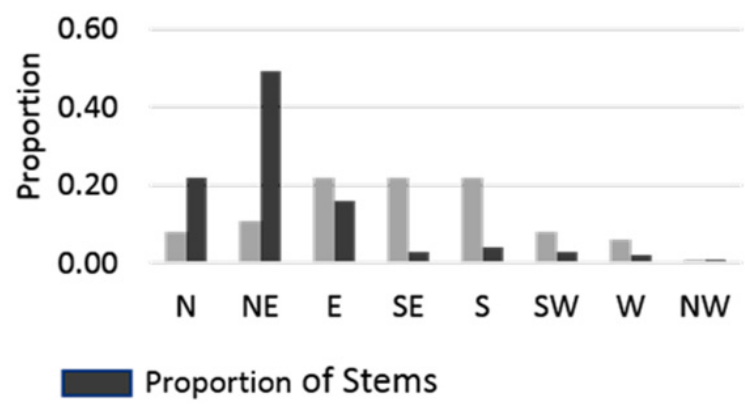

Distance to streams was more variable for adults at CHE than at PAR where stems tended to be closer to stream channels. The distance to streams for saplings was $<100 \mathrm{~m}$ for all saplings at CHE, while the saplings at PAR were more variable in distance to streams and the maximum distance approached $200 \mathrm{~m}$ (Figure 6). This difference was reflected in a higher median distance for saplings at PAR. Wilcoxon rank-sum tests indicated that median sapling distance differed between CHE and PAR $(p<0.01)$, but that there was no statistical difference between the sites' median distance of adult stems from streams. 
Figure 6. Distribution of distance to streams for adults and saplings at CHE (top) and PAR (bottom). At CHE adult stems were much more widely distributed with distance from streams whereas saplings were all found within $100 \mathrm{~m}$ from a stream. At PAR adults and saplings were similarly distributed with distance from streams though saplings had a greater maximum distance and the median was slightly higher.
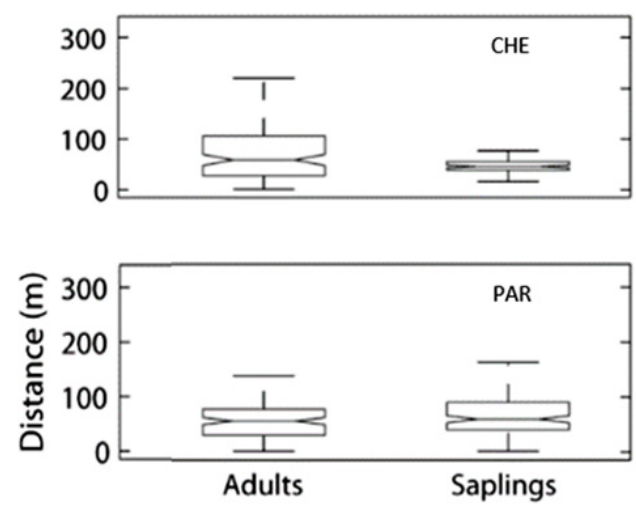

\section{Discussion}

The QULO stand at CHE is experiencing a population decline and demographic shift toward a small, young stand as well as a spatial shift from a widely dispersed, savannah-like stand, to a riparian woodland. This pattern can be understood as a decrease in resilience of QULO in this location due to factors such as a warming, drying climate that led to reduced water availability and could continue until no more micro-climate refugia exist. Other historical land uses, such as grazing, mowing, or use of the land in film production can be understood as connections between landscape elements that introduced energy, matter, or information to effectively reduce the resilience of QULO in this location by directly or indirectly retarding regeneration. Evidence of mowing in different portions of the sites is visible in historical aerial photography and could have drastically influenced regeneration patterns but no reliable record is available. Until the point where QULO refugia have been entirely removed from the landscape, regeneration could occur if the climate somehow cooled and more water became available. At the point where QULO have been removed from the landscape, a threshold exists such that repopulation cannot occur without some new process to reintroduce the species. In terms of the adaptive cycle mentioned above, QULO at CHE are in the "backloop" of release and reorganization. Whether QULO will continue to exist at this site or other species will establish in the former QULO habitat remains to be seen. An example of this process may have occurred at Rancho Sierra Vista (RSV), a former QULO stand in the Santa Monica Mountains. Valley oak at RSV were surveyed as part of a QULO assessment in the 1980s [46]; however, in 2009 only two stems in poor condition could be observed there (Hayes, pers. observation).

The stand at PAR has a much more evenly distributed size-class structure, is regenerating well, and shows little sign of spatial shifts in habitat as compared with adult establishment sites. While PAR is exposed to the same landscape-level climate conditions as CHE, increased streamflow and greater availability of suitable micro-climate habitat have enhanced the conservation stage at this site. In spite of current regeneration and stand demographics, a decrease in imported water from upstream development would likely lead to a contraction of the stand to the Medea Creek channel—like the 
contraction of regeneration at CHE to the riparian corridor. Eventually, a similar size-class histogram as that seen at CHE would develop. Other site-specific factors are likely impacting the regeneration of QULO at the two sites including browsing and seed predation, competition from non-native species, and soil compaction from grazing and agriculture.

Both sites are near features where humans have heavily modified the landscape and are experiencing the same regional-scale cycles of precipitation; however, the watersheds of the two sites have very different upstream land cover characteristics. Of particular interest is urban land cover and its associated impervious surface area, which increases direct runoff to stream channels and stream discharge. Urban land cover is also associated with "imported water", or municipal water brought from outside the region to supplement precipitation. Stream gauge data from Malibu Creek, downstream from both CHE and PAR, show that stream discharge increased and stabilized at higher levels following increased residential development and the arrival of imported water [49]. The result of increased urban impervious surface combined with imported water availability, for residential and commercial use, is greater runoff and stream discharge than the watershed would have experienced before development. Comparison of historical landscape photographs reveals that in spite of drier climate conditions, Madea Creek, which runs along the eastern edge of PAR has become a riparian woodland zone, whereas in the 1950s it was free of woody trees and shrubs, flowing intermittently through QULO savanna. Cheeseboro Canyon is still an intermittent stream today, though it too supports riparian species, only a few QULO saplings are found along this stream channel. Most of the saplings found at CHE are below the convergence of Cheeseboro Canyon and Palo Commado Canyon, which has some low-density residential development extending up the canyon from the CHE site.

In terms of a landscape system, QULO is resilient in the sense that it remains viable in combination with the increased availability of water that has come with urbanization. Without the imported water, however, QULO is not resilient to changing conditions as evidenced by regeneration failure at CHE. In this way, the resilience of QULO can best be understood as the emergent property of landscape features linked in a particular way. The longer term resilience of QULO in this landscape system, however, seems dubious in that the possibility of importing water into this arid landscape will become more difficult over time such that a landscape scale reorganization my not include QULO stands. To answer the question of "resilience of what to what" in the current organization of this system, the presence of QULO is resilient to climate change. In terms of sustainability, however, the likely link between QULO and imported water is not a sustainable one.

\section{Conclusions}

A resilience approach to landscape conservation requires flexibility and is more challenging than traditional conservation approaches because it requires an openness to a range of possibilities rather than a familiar or desired state. A landscape managed with resilience as a guiding principle rather than enumerated diversity and structural measures will look different over the years and may even look "unhealthy" in terms of past experience, but will maintain ecological functions and environmental services. To manage a resilient landscape will require understanding the ecological functions and environmental services that need to be maintained, and what the thresholds on biophysical variables are to maintain them. In addition to community composition and structure, managers will have to 
understand landscape composition, structure, and function to plan for potential spatial interactions and teleconnections across the landscape. Regional trends toward a drier and warmer climate are expected to force QULO regeneration and recruitment into microclimate refugia - the cooler, wetter sites-within landscapes [40]. As long as QULO remains present with population structure, function, and spatial pattern within the thresholds necessary for maintaining environmental services to the landscape ecosystem it can be thought of as resilient even as the landscape changes. As is demonstrated in this paper, other changes in the landscape may enhance or degrade the resilience of QULO at the scale of the stand. This sort of systems approach to understanding and maintaining resilience requires an interdisciplinary approach including both physical and social science perspectives.

Other questions remain about the future of QULO in Southern California and elsewhere in the state. As QULO responds to changes in the surrounding landscape and climate, it faces new ecological conditions and new community interactions and dynamics. How will QULO be able to compete with riparian vegetation and with CSS species on hillsides under changing climatic conditions and increasing urban development? The lack of general conclusions that can be drawn from previous research on individual sites suggests that both site-level factors and scale of analysis must be important and future work needs to account for differences among sites and the effect that the chosen scale of analysis has on the results. Here we compared two sites within one watershed and discussed how water availability at multiple scales can enhance the understanding of QULO patterns at these two sites. Examining and considering site and scale-dependent effects may complicate analysis, but could prove beneficial to conservation strategies for QULO communities which are likely affected by processes operating across sites at multiple scales.

\section{Acknowledgments}

The authors thank the California State University, Northridge, College of Social and Behavioral Sciences for supporting data collection, and the US National Park Service, Santa Monica Mountains National Recreation Area staff, especially Marti Witter and Christy Brigham for advice and insights on the Santa Monica Mountains landscape and valley oak in southern California.

\section{Author Contributions}

This manuscript was a close collaboration between authors Hayes and Donnelly. The methods and results are based on work conducted by Hayes, though both authors contributed to presenting and discussing the results in a landscape conservation framework informed by resilience and complexity theory.

\section{Conflicts of Interest}

The authors declare no conflicts of interest.

\section{References}

1. Baron, J.S.; Gunderson, L.; Allen, C.D.; Fleishman, E.; McKenzie, D.; Meyerson, L.A.; Oropeza, J.; Stephenson, N. Options for national parks and reserves for adapting to climate change. Environ. Manag. 2009, 44, 1033-1042. 
2. Hobbs, R.J.; Hallett, L.M.; Ehrlich, P.R.; Mooney, H.A. Intervention ecology: Applying ecological science in the Twenty-First Century. BioScience 2011, 61, 442-450.

3. Allen, T.F.H.; Starr, T.B. Hierarchy: Perspectives for Ecological Complexity; University of Chicago Press: Chicago, IL, USA, 1982.

4. Phillips, J.D. The perfect landscape. Geomorphology 2007, 84, 159-169.

5. Cundill, G.; Cumming, G.S.; Biggs, D.; Fabricius, C. Soft systems thinking and social learning for adaptive management. Conserv. Biol. 2011, 26, 13-20.

6. Marsh, G.P. Man and Nature: Or, Physical Geography as Modified by Human Action; Scribner: New York, NY, USA, 1864.

7. Grumbine, R.E. What is ecosystem management? Conserv. Biol. 1994, 8, 27-38.

8. Grumbine, R.E. Reflections on "What is ecosystem management?" Conserv. Biol. 1997, 11, 41-47.

9. Koontz, T.M.; Bodine, J. Implementing ecosystem management in public Agencies: Lessons from the U.S. Bureau of land management and the forest service. Conserv. Biol. 2008, 22, 60-69.

10. Noss, R.F. A regional approach to maintain diversity. BioScience 1983, 33, 700-706.

11. Haber, W. Using landscape ecology in planning and management. In Changing Landscapes: An Ecological Perspective; Zonneveld, E.S., Forman, R.T.T., Eds.; Springer: New York, NY, USA, 1990; pp. 217-232.

12. Christensen, N.L; Bartuska, A.M.; Brown, J.H.; Carpenter, S.; D’Antonio, C.; Francis, R.; Franklin, J.F.; MacMahon, J.A.; Noss, R.F.; Parsons, D.J.; et al. The report of the ecological society of America Committee on the scientific basis for ecosystem management. Ecol. Appl. 1996, 6, 665-691.

13. Gobster, P.H. An ecological aesthetic for forest landscape management. Landsc. J. 1999, 18, 54-64.

14. Seto, K.C.; Reenberg, A.; Boone, C.G.; Fragkias, M.; Haase, D.; Langanke, T.; Marcotullio, P.; Munroe, D.K.; Olah, B.; Simon, D. Urban land teleconnections and sustainability. Proc. Natl. Acad. Sci. USA 2012, 109, 7687-7692.

15. Turner, M.G. Landscape ecology: The effect of pattern on process. Ann. Rev. Ecol. Syst. 1989, 20, 171-197.

16. Turner, M.G.; Gardner, R.H.; O’Neill, R.V. Landscape Ecology in Theory and Practice: Pattern and Process; Springer: New York, NY, USA, 2002.

17. Farina, A. Principles and Methods in Landscape Ecology; Springer: Dordrecht, The Netherlands, 2006.

18. US National Park Service. Rim of the Valley Corridor Special Resource Study. Available online: http://www.nps.gov/pwro/rimofthevalley/index.htm (accessed on 18 April 2014).

19. Walker, B.; Holling, C.S.; Carpenter, S.R.; Kinzig, A. Resilience, adaptability and transformability in social ecological systems. Ecol. Soc. 2004, 9, 1-9.

20. Homer-Dixon, T. The Upside of Down: Catastrophe, Creativity, and the Renewal of Civilization; Island Press: Washington, DC, USA, 2008.

21. Malanson, G.P. Considering complexity. Ann. Assoc. Am. Geogr. 1999, 89, 746-753.

22. Stoddart, D.R. Geography and the ecological approach: The ecosystem as a geographical principle and method. Geography 1965, 50, 242-252.

23. Stoddart, D.R. On Geography: And Its History; Blackwell: Oxford, UK, 1986.

24. Stonier, T. Information as a basic property of the universe. Biosystems 1996, 38, 135-140 
25. Manson, S.M. Simplifying complexity: A review of complexity theory. Geoforum 2001, 32, 405-414.

26. O’Sullivan, D. Complexity science and human geography. Trans. Instit. British Geogr. 2004, 29, 282-295.

27. McLaughlin, B.C.; Zavaleta, E.S. Regional and temporal patterns of natural recruitment in a California endemic oak and a possible "research reserve effect". Diver. Distrib. 2013, 19, 1440-1449.

28. Franklin, J.F.; MacMahon, J.A. Enhanced: messages from a mountain. Science 2000, 288, 1183-1184.

29. Holling, C.S.; Gunderson, L.H. Resilience and adaptive cycles. In Panarchy: Understanding Transformations in Human and Natural Systems; Island Press: Washington, DC, USA, 2002; pp. 25-62.

30. Holling, C.S.; Gunderson, L.H; Peterson, G.D. Chapter 3. Sustainability and panarchies. In Panarchy: Understanding Transformations in Human and Natural Systems; Island Press: Washington, DC, USA, 2002; pp. 63-102.

31. Carpenter, S.; Walker, B.; Anderies, J.M.; Abel, N. From metaphor to measurement: Resilience of what to what? Ecosystems 2001, 4, 765-781.

32. Griffin, J.R. Regeneration in Quercus lobata savannas, Santa Lucia Mountains, California. Am. Midl. Nat. 1976, 95, 422-435.

33. Brown, RW.; Davis, F.W. Historical mortality of Valley Oak (Quercus lobata, Nee) in the Santa Ynez Valley, Santa Barbara County, 1938-1989. In Proceedings of the Symposium on Oak Woodlands and Hardwood Rangeland Management, Davis, CA, USA, 31 October-2 November 1990; General Technical Report PSW-126; Standiford, R.B., Tech. Coord., Eds.; USDA Forest Service, Pacific Southwest Research Station: Berkley, CA, USA, 1991;; pp. 202-207.

34. Sork, V.L.; Davis, F.W.; Smouse, P.E.; Apsit, V.J.; Dyer, R.J.; Fernandez, J.F.; Kuhn, B. Pollen movement in declining populations of California Valley Oak, Quercus lobata: Where have all the fathers gone? Mol. Ecol. 2002, 11, 1657-1668.

35. Pavlik, B.M.; Muick, P.; Johnson, S.; Popper, M. Oaks of California; Cachuma Press: Los Olivos, CA, USA, 1991.

36. Kueppers, L.M.; Snyder, M.A.; Sloan, L.C.; Zavaleta, E.S.; Fulfrost, B. Modeled regional climate change and California endemic oak ranges. Proc. Natl. Acad. Sci. USA 2005, 45, 16281-16286.

37. Tyler, C.M.; Kuhn, B.; Davis, F.W. Demography and recruitment limitations of three oak species in California. Q. Rev. Biol. 2006, 81, 127-152.

38. Zavaleta, E.S.; Hulvey, K.B.; Fulfrost, B. Regional patterns of recruitment success and failure in two endemic California oaks. Divers. Distrib. 2007, 13, 735-745.

39. Sork, V.L.; Davis, F.W.; Westfall, R.; Flint, A.; Ikegami, M.; Wang, H.; Grivet, D. Gene movement and genetic association with regional climate gradients in California Valley Oak (Quercus lobata Née) in the face of climate change. Mol. Ecol. 2010, 19, 3806-3823.

40. McLauglin, B.C.; Zavaleta, E.S. Predicting species responses to climate change: Demography and climate microrefugia in California Valley Oak (Quercus. lobata). Glob. Chang. Biol. 2012, $18,2301-2312$.

41. Bolsinger, C.L. The Hardwoods of California's Timberlands, Woodlands, and Savannas; Resources Bulletin PNW-RB-148; USDA Forest Service, Pacific Northwest Research Station: Portland, OR, USA, 1988. 
42. Bartolome, J.W.; Muick, P.C.; McClaran, M.P. Natural regeneration of California hardwoods. In Proceedings of the Symposium on Multiple-Use Management of California's Hardwood Resources, San Luis Obispo, CA, USA, 12-14 November 1986; General Technical Report PSW-100; Plumb, T.R., Pillsbury, N.H., Eds.; USDA Forest Service, Pacific Southwest Forest and Range Experiment Station: Berkely, CA, USA, 1987;pp.: 26-31.

43. Howard, J.L. Quercus lobata. In Fire Effects Information System; USDA Forest Service, Rocky Mountain Research Station: Fort Collins, CO, USA, 1992. Available online: http://www.fs.fed.us/ database/feis/plants/tree/quelob/all.html (accessed on 18 April 2014).

44. Davis, F.W.; Tyler, C.M.; Mahall, B.E. Consumer control of oak demography in a Mediterranean climate savanna. Ecosphere 2011, 2, 1-21.

45. White, K.L. Structure and composition of foothill woodland in central coastal California. Ecology 1966, 47, 229-237.

46. Thomas, T.W. Population structure of the Valley Oak in Santa Monica Mountains national recreation area. In Proceedings of the Symposium on Multiple-Use Management of California's Hardwood Resources, San Luis Obispo, CA, USA, 12-14 November 1986; General Technical Report PSW-100; Plumb, T.R., Pillsbury, N.H., Eds.; USDA Forest Service, Pacific Southwest Research Station: Berkeley, CA, USA, 1987; pp. 335-340.

47. Tyler, C.M.; Davis, F.W.; Mahall, B.E. The relative importance of factors affecting age-specific seedling survival of two co-occurring oak species in southern California. For. Ecol. Manag. 2008, 255, 3063-3074.

48. Danielsen, K.C.; Halvorson, W.L. Valley Oak seedling growth associated with selected grass species. In Proceedings of the Symposium on Oak Woodlands and Hardwood Rangeland Management, Davis, CA, USA, 31 October-2 November 1990; General Technical Report PSW-126; Standiford, R.B., Ed.; USDA Forest Service, Pacific Southwest Research Station: Berkley, CA, USA, 1991; pp. 9-13.

49. Orton, R. Las Virgenes Municipal Water District, Calabasas, CA, USA. Personal communication, 2013.

50. Fry, J.; Xian, G.; Jin, S.; Dewitz, J.; Homer, C.; Yang, L.; Barnes, C.; Herold, N.; Wickham, J. Completion of the 2006 national land cover database for the conterminous United States. Photogramm. Eng. Remote Sens. 2006, 77, 858-864.

51. Environmental Systems Research Institute (ESRI). Arc 9.2; ESRI: Redlands, CA, USA, 2006.

52. Hayes, J.J. Heterogeneity in recruitment and habitat patterns of Valley Oak (Quercus lobata Nee) at the site and landscape scale in the Santa Monica Mountains, California, USA. Plant. Ecol. 2013, 214, 929-940.

(C) 2014 by the authors; licensee MDPI, Basel, Switzerland. This article is an open access article distributed under the terms and conditions of the Creative Commons Attribution license (http://creativecommons.org/licenses/by/3.0/). 